Vol. 3, No. 1, 2021

https://doi.org/10.23939/cds2021.01.011

UDC 519.2 (035); 519.213.1;519.222

P. Kosoboutskyy, M. Karkulovska

Lviv Polytechnic National University

\title{
MODELING OF ATOMIC SYSTEMS AND POSITIONING OF ELEMENTS OF NOBLE GASES OF THE PERIODIC TABLE BY PROPORTIONAL DIVISION METHOD
}

(C) Kosoboutskyy P., Karkulovska M., 2021

This paper studies regularities of proportional division, on the basis of which we show the possibility of effective application of the golden section method to modeling regularities of atomic systems and positioning of elements of noble gases of the periodic table. It is illustrated that by partial reconstruction of the Mendeleev tables, the elements of noble gases can be arranged along lines whose slope tangents in the coordinate system "the atomic number - the relative atomic mass" are in close agreement with the sequence of inverse Fibonacci numbers. It was shown that given the correct slope of axes, slope tangents of the corresponding lines does not change. table.

Keywords - Golden section, Fibonacci numbers, proportional division, atom, periodic

\section{Introduction}

The method of golden section (GS) of the whole system divided into two unequal parts was applied for various modeling problems [1-16], including problems related to the modeling of atomic $[1-2,9,11]$ and quantum [15,16] systems. Thus, in [1,17-19], by means of the Cartesian axis system scaling, it was illustrated that by partial reconstruction of the periodic system, the elements of noble gases can be arranged along lines whose slope tangents in the coordinate system 'the atomic number - the relative atomic mass' are in close agreement with the sequence of inverse Fibonacci numbers:

$$
1^{-1}, 1^{-1}, 2^{-1}, 3^{-1}, 5^{-1}, 8^{-1}, 13^{-1} \text {. }
$$

This paper studies regularities of proportional division, on the basis of which we show the possibility of effective application of the GS method to modeling regularities of atomic systems and arrangement of the elements of noble gases of the periodic table [1,17-19].

\section{The model of Bohr atom}

It is known [20-21] that the mathematical model of structure arrangement using the GS method with quantitative characteristics $\varphi, \Phi$ is:

$$
\frac{L}{x}=\frac{x}{L-x} \Rightarrow\left\{\begin{array} { l l } 
{ \varphi = \frac { x } { L } : } & { \varphi ^ { 2 } + \varphi - 1 = 0 , } \\
{ \Phi = \frac { L } { x } : } & { \Phi ^ { 2 } - \Phi - 1 = 0 , }
\end{array} \Rightarrow \left\{\begin{array}{l}
\varphi=\frac{-1+\sqrt{5}}{2}=0,618 \ldots, \\
\Phi=\left|\frac{-1+\sqrt{5}}{2}\right|=0,618 \ldots
\end{array}\right.\right.
$$

at the phase point with coordinates $p=+1, q=-1$. In the Cartesian plane $p 0 q$, the axes of which divide it into four quadrants, the point with coordinates $p=+1, q=-1$ is located in the second quadrant $p>0, q<0$ in the phase direction 


$$
-p+q+1=0
$$

which is parallel to the first $K=1$ root straight line

$$
-K p+q \pm K^{2}=0, \quad K=0, \pm 1, \pm 2, \pm 3, \ldots
$$

and shifted right by a unity $|\Delta q|=1$.

Along the direction (4) modules

$$
|p|=|q|=k,
$$

coincide, so in the second $p>0, q<0$ and the third $p<0, q<0$ quadrants the roots of a square threeterm

$$
x^{2} \pm p x-q=0
$$

are quadratically irrational and exhibit the GS properties (Fig. 1). As follows from this figure, in the first and third quadrants there are areas with imaginary roots (6). Therefore, let us limit ourselves to the corresponding analysis within the second quadrant.

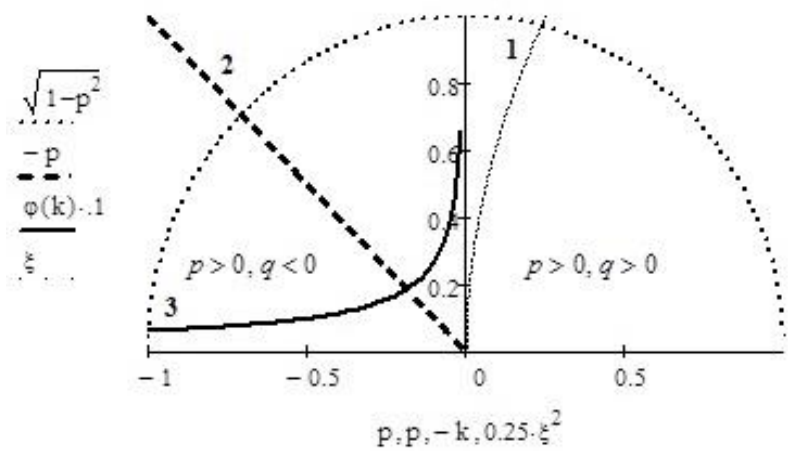

Fig. 1 .

As we can see in Fig. 1, in the second quadrant, with continuous change of $k$ along the direction (3) (line 2), the roots satisfy the regularities:

$$
\varphi(k, k)^{2}+k \cdot \varphi(k, k)-k=0 \Rightarrow\left\{\begin{array}{l}
\varphi_{ \pm}(k, k)=\frac{k}{2}(-1 \pm \sqrt{1+4 / k}), \\
\varphi_{+}(k, k)+\varphi_{-}(k, k)=-k, \\
\varphi_{+}(k, k) \cdot \varphi_{-}(k, k)=-k,
\end{array}\right.
$$

that is, the graph of the roots $\varphi(k)_{+}$is in the form of parabola 3 (given in Fig. 1 for a positive solution only).

A positive solution $\Phi(k)_{+}$in the third $p\left\langle 0, q\left\langle 0\right.\right.$ quadrant related to $\varphi(k)_{+}$of the equation [22-25]

$$
\Phi(k)_{+}=\frac{k}{\varphi(k)_{+}} .
$$

Therefore, now let us turn the solutions $\varphi(k)_{+}$and $\Phi(k)_{+}$into

$$
\varphi(k)=\frac{k}{2}(-1+D(k)), \quad \Phi(k)=\frac{k}{2}(+1+D(k)),
$$

and consider their plurality, for which the exact square is the discriminant:

$$
D(k)=1+\frac{4}{k_{M}}=M^{2} \Rightarrow M>1 .
$$


The set of integers $M$ corresponds to the set of values $k_{M}$

$$
k_{M}=\frac{4}{M^{2}-1} \Rightarrow M \geq 2 \text {. }
$$

In the interval from

$$
\left.k\right|_{M=2}=\frac{4}{3} \quad \text { to }\left.\quad k\right|_{M=\infty} \rightarrow 0
$$

the values of (12) form a nonlinearly descending sequence

$$
k_{M}: 4 \cdot\left(\frac{1}{3}, \frac{1}{8}, \frac{1}{15}, \frac{1}{24}, \frac{1}{35}, \frac{1}{48}, \frac{1}{63}, \frac{1}{80}, \frac{1}{99}, \frac{1}{120}, \frac{1}{143}, \frac{1}{168}, \frac{1}{195}, \frac{1}{224}, \ldots\right)
$$

in which there is the difference between the two denominators of adjacent numbers. This is a decreasing dependence, the graph of which is shown in Fig. 2. Given values $k$, functions $\varphi(M)$ and $\Phi(M)$ are:

$$
\left\{\begin{array} { l } 
{ \varphi ( M ) = \frac { 2 } { M + 1 } } \\
{ \Phi ( M ) = \frac { 2 } { M - 1 } }
\end{array} \Rightarrow \left\{\begin{array} { l } 
{ \varphi ( M ) - \Phi ( M ) = - \frac { 4 } { M ^ { 2 } - 1 } } \\
{ \varphi ( M ) \cdot \Phi ( M ) = \frac { 4 } { M ^ { 2 } - 1 } } \\
{ \varphi ( M ) + \Phi ( M ) = \frac { 4 M } { M ^ { 2 } - 1 } }
\end{array} \Rightarrow \left\{\begin{array} { l } 
{ \varphi ( M ) - \Phi ( M ) = - \varphi ( M ) \cdot \Phi ( M ) } \\
{ \varphi ( M ) ^ { 2 } - \Phi ( M ) ^ { 2 } = - \frac { 1 6 M ^ { 2 } } { ( M ^ { 2 } - 1 ) ^ { 2 } } }
\end{array} \Rightarrow \left\{\begin{array}{l}
\frac{1}{\varphi(M)}-\frac{1}{\Phi(M)}=1 \\
\frac{1}{\varphi(M)}+\frac{1}{\Phi(M)}=M
\end{array}\right.\right.\right.\right.
$$

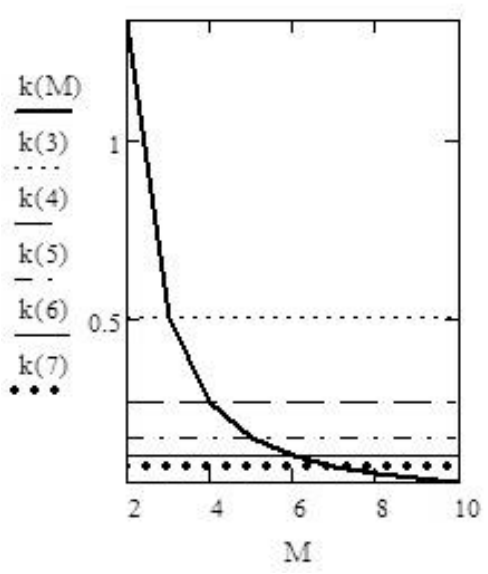

Fig. 2.

The sequence (13) also includes a value $k=1$ corresponding to the classic golden section. The differences between two denominators of adjacent numbers

$$
\begin{aligned}
& 8-3=5=3+2=3+2 \cdot 1, \\
& 15-8=7=5+2=3+2 \cdot 2, \\
& 24-15=9=7+2=3+2 \cdot 3, \\
& 35-24=11=9+2=3+2 \cdot 4, \\
& 48-35=13=11+2=3+2 \cdot 5, \\
& 63-48=15=13+2=3+2 \cdot 6, \ldots
\end{aligned}
$$

change according to the integer law $(3+2 \cdot M)$. Given 


$$
\varphi_{ \pm}(k, k)=\varphi(M)=\frac{2}{M+1}=\frac{1}{2} \cdot\left\{\begin{array}{c}
k=4 / 3, \\
k=4 / 8, \\
k=4 / 15, \\
k=4 / 24, \\
\ldots
\end{array}\right)-1 \pm\left\{\begin{array}{c}
M=2, \\
M=3, \\
M=4, \\
M=5, \\
\ldots
\end{array}\right)=\left\{\begin{array}{c}
2 / 3, \\
2 / 4, \\
2 / 5, \\
2 / 6, \\
\ldots
\end{array}\right.
$$

and

$$
\Phi(M)=\frac{k}{\varphi(M)}=\frac{4 /\left(M^{2}-1\right)}{2 /(M+1)}=\frac{2}{M-1}=\left\{\begin{array}{c}
M=2, \Phi(2)=2, \\
M=3, \Phi(3)=1, \\
M=4, \Phi(4)=2 / 3, \\
M=5, \Phi(5)=2 / 4, \\
\ldots
\end{array}\right.
$$

the values of the solutions (14) form the series:

$$
\left\{\begin{array}{lccccccccl}
M & 2 & 3 & 4 & 5 & 6 & 7 & 8 & 9 & 10 \\
\varphi(M) & 2 / 3, & 2 / 4, & 2 / 5, & 2 / 6, & 2 / 7, & 2 / 8, & 2 / 9, & 2 / 10, & 2 / 11, \ldots \\
\Phi(M) & 2 & 1 & 2 / 3 & 2 / 4 & 2 / 5 & 2 / 6 & 2 / 7 & 2 / 8 & 2 / 9
\end{array}\right.
$$

$\varphi(M)$ and $\Phi(M)$ satisfy the ratio

$$
\varphi(M)=\Phi(M+2)
$$

the implementation of which is confirmed in the form of Table 1, which shows the calculated first eleven values of the functions $\varphi(M)$ and $\Phi(M)$. The regularity of changing the numerical values of the denominator in the sequence (18), as the difference between the values of the two adjacent denominators, follows the law (15), as a series of natural numbers $1,2,3,4,5, \ldots$, transformed with constant coefficients. Therefore, the ratio $1+4 / k=M^{2}$ is interesting because it is similar to the allowed atom's internal energy values in the Bohr model from number $K$ :

$$
W(\mathrm{~K})=-\frac{m e^{4}}{2 \eta^{2}} \frac{1}{\mathrm{~K}^{2}}
$$

Table 1.

\begin{tabular}{|c|c|c|c|c|c|c|c|c|c|c|}
\hline$M$ & $\mathbf{2}$ & $\mathbf{3}$ & $\mathbf{4}$ & $\mathbf{5}$ & $\mathbf{6}$ & $\mathbf{7}$ & $\mathbf{8}$ & $\mathbf{9}$ & $\mathbf{1 0}$ & $\mathbf{1 1}$ \\
\hline$k(M)$ & $\frac{4}{3}$ & $\begin{array}{l}\frac{4}{8}= \\
=0,5\end{array}$ & $\begin{array}{l}\frac{4}{15}= \\
0,267\end{array}$ & $\begin{array}{l}\frac{4}{24}=0,167 \\
=0,114\end{array}$ & $\begin{array}{l}\frac{4}{35}= \\
=0,083\end{array}$ & $\begin{array}{l}\frac{4}{48}= \\
0,063\end{array}$ & $\begin{array}{l}\frac{4}{63}=0,05 \\
=0,04\end{array}$ & $\begin{array}{l}\frac{4}{80}=0,033 \\
=\end{array}$ & $\begin{array}{l}\frac{4}{99}= \\
=0,120\end{array}$ \\
\hline$\varphi(M)$ & $\mathbf{0 , 6 6 7}$ & $\mathbf{0 , 5}$ & $\mathbf{0 , 4}$ & $\mathbf{0 , 3 3 3}$ & $\mathbf{0 , 2 8 6}$ & $\mathbf{0 , 2 5}$ & $\mathbf{0 , 2 2 2}$ & $\mathbf{0 , 2}$ & $\mathbf{0 , 1 8 2}$ & $\mathbf{0 , 1 6 7}$ \\
\hline$\Phi(M)$ & $\mathbf{2}$ & $\mathbf{1}$ & $\mathbf{0 , 6 6 7}$ & $\mathbf{0 , 5}$ & $\mathbf{0 , 4}$ & $\mathbf{0 , 3 3 3}$ & $\mathbf{0 , 2 8 6}$ & $\mathbf{0 , 2 5}$ & $\mathbf{0 , 2 2 2}$ & $\mathbf{0 , 2}$ \\
\hline
\end{tabular}


The graphic illustration of the diagram of the position of energy levels by law $1 / M^{2}$, is shown in Fig. 2

\section{The periodic table of elements}

It is known in atomic physics [25] that every period of elements from the second to the seventh is terminated by an inert atom. Fig. 3 (a) presents the dependencies of the atomic masses of each element in a given period as the fraction of the atomic mass of the last element of a given period, that is, an inert element. Different slopes of direct linear dependencies for different periods of chemical elements prompted the author [1,17-19] to think that it is possible to relate them to the regularities of inverse Fibonacci numbers:

$$
\frac{1}{1}, \frac{1}{1}, \frac{1}{2}, \frac{1}{3}, \frac{1}{5}, \frac{1}{8}, \frac{1}{13}, \ldots .
$$

However, in our opinion, the author's conclusion is wrong and is caused by the choice of the scale on coordinate axes. Indeed, to exclude its influence along the abscissa axis, we performed statistical processing of the experimental data in Fig. 3(a) by the least squares method and revealed that the slopes of all rectilinear dependences of the atomic masses of each element in a given period as the fraction of the atomic mass of the last element of a given period, practically does not depend on the period number of the chemical elements (Fig. 3(b))

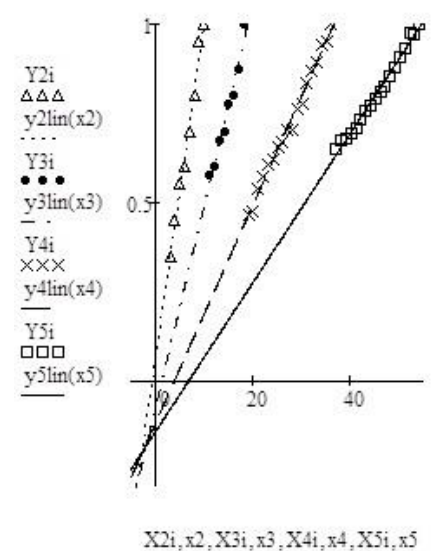

a)

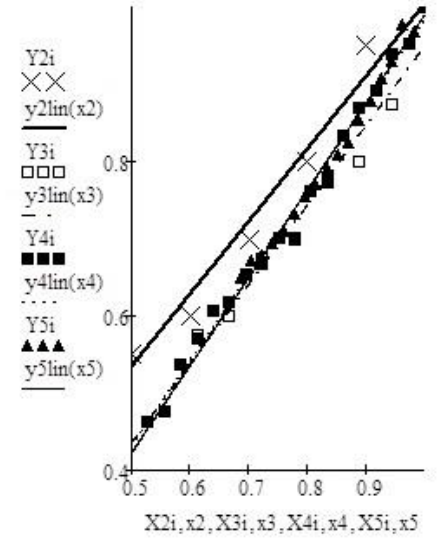

b)

Fig. 3.

\section{Conclusions}

In this paper, on the basis of the known equation of the proportional division of a system parameter into two unequal parts (golden section), we developed a recurrent model of atomic levels and positioning of noble gases of the periodic table of elements. By processing the data in coordinate system 'the atomic number - the relative atomic mass' by the least squares method, it was shown that given the correct slope of axes, slope tangents of the corresponding lines does not change.

- Reference

1. J. Boeyens, D. Levendis. Number Theory and the Periodicity of Matter. Springer Science+Business Media B.V. 2008.

2. I. Affleck, Nature, 464, 18 (2010) From Web Resource: http://www.readcube.com/articles/10.1038/464362a.

3. T. Al-Ameri, Applied Sciences, 8 No1, 54 (2018).

4. D. Gratia, Physics-Uspekhi, 156 No2, 347 (1988).

5. N.V. Grushina, P.V. Korolenko, P.A. Perestoronin, Preprint of the Physics Department of Moscow State University. No6, (2007).

6. R. Beltrán, F. Gómez, R. Franco et.al., Lat. Am. J. Phys. Educ. 7 No4, 621 (2013).

7. B. Denardo, Am. J. Phys. 67 No11, 981 (1999). 
8. T. Srinivasan, Am.J.Phys., 60 No5, 461-462 (1992).

9. D. Shechtman, I. Blech, D. Gratias, et.al., Phys.Rev.Lett. 53, 1951 (1984).

10. A. Rostami, S. Matloub, Laser Physics, 14 No12, 1475 (2004).

11. R. Heyrovska, Molecular Physics, 103, 877 (2005).

12. V. Pletser. Fibonacci Numbers and the Golden Ratio in Biology, Physics, Astrophysics, Chemistry and Technology: A Non-Exhaustive Review. From Web Resource: https://arxiv.org/ftp/arxiv/papers/1801/1801.01369.pdf.

13. T. Omotehinwa, S. Ramon, International J. of Computer and Information Technology. 04 No2, 630 (2013).

14. A. Kharitonov, Applied Physics (Russia), No1, 5 (2007).

15. O. Pashev, S. Nalci, J.Phys.A: math.Theor., 45, 015303-15 (2012).

16. F. Kayn, M. Williams, D. Anderson. Nanophotonics (Ed. D.L. Andrews, J.-M. Nunzi, A. Ostendorf.Proc.of SPIE. 9884, April 2016, P. 988434-35) (2016).

17. S.I. Yakushko. Real physical processes. From Web Resource: http://ukr.rusphysics.ru/files/Yakusko.Simmetrichnyi.pdf .

18. S.I. Yakushko. Fibonacci regularity in the periodic system elements of D.I.Mendeleev. From Web Resource: http://ukr.rusphysics.ru/files/Yakuschko.Fibonachchieva\%20sakonomernost.pdf.

19. N. Shilo, A. Dinkov. Academy of Trinitarianism. (M.: 77-6567, 2007).

20. N.N. Vorobyov, Fibonacci Numbers, (M.: 1961).

21. V.S. Smirnov, The Golden Section - Basic the Mathematics and Physics in Future. The Spiral of the Universe Development, (San-Peterb. RIO HOUIPT, 2002).

22. P. Kosobutskyy, Jour. of Electronic Research and Application (Australia), 3 No3, 8 (2019).

23. P. Kosobutskyy. International Conference Algebra and Analysis with Application. July 1-4 2018, Ohrid, Republic of Macedonia]

24. P.S. Kosobutskyy, M.S. Karkulovska, Bulletin of the Lviv Polytechnic National University. Collection of scientific works. Scientific publication. Series: Computer Design Systems. Theory and practice. №908, 75 (2018)

25. P.R. Gaida. Atomic: a Textbook for student of Phys.spec.un-ty. (Lviv: Lviv university, 1965).

П. Кособуцький, М. Каркульовська

Національний університет Львівська політехніка

\title{
МОДЕЛЮВАННЯ АТОМНИХ СИСТЕМ ТА ПОЗИЦІОНУВАННЯ ЕЛЕМЕНТІВ БЛАГОРОДНИХ ГАЗІВ ПЕРІОДИЧНОЇ СИСТЕМИ МЕТОДОМ ПРОПОРЦИЙНОГО ПОДІЛУ
}

\author{
(C) Кособуцький П.С., Каркульовська М.С., 2021
}

У даній роботі досліджені закономірності пропорційного поділу, на основі яких показана можливість коректного застосування методу золотого перерізу для моделювання закономірностей атомних систем та позиціювання елементів благородних газів періодичної системи. Проілюстровано, що шляхом часткової реконструкції у таблиці Менделеєва елементи благородних газів можна розташувати вздовж ліній, дотичні нахилу яких у системі координат ' атомний номер - відносна атомна маса' тісно узгоджуються 3 послідовністю обернених чисел Фібоначчі. I при правильному нахилі осей дотичні нахилу відповідних прямих не змінюються.

Ключові слова - Золотий переріз, числа Фібоначчі, пропорційний поділ, атом, періодична система. 